\title{
Turismo como fenômeno social e suas implicações no espaço rural
}

\author{
Tourism as a social phenomenon and its implications for rural space
}

Maysa Sena de Carvalho, Marutschka Martini Mœsch

\section{RESUMO}

Este artigo apresenta uma reflexão teórica a respeito das definições para turismo, em toda sua complexidade. Apresentamos as concepções realizadas por diferentes pensamentos do tema. Sendo assim, contribuiremos por meio de uma releitura das escolas de pensamento e quadros interpretativos, formas de sistematização, e principais correntes de estudos do turismo realizados por MCESCH (2004). Transpondo esta reflexão para a explicitação do conceito que norteia a produção associada ao turismo no uso do espaço rural em unidades de produção da agricultura familiar, neste contexto se inclui o estudo dos impactos sobre as relações de gênero no desenvolvimento das atividades relacionadas. Utiliza-se de uma análise documental de natureza exploratória, com abordagem do turismo. Conclui-se que é preciso compreender o turismo como fenômeno acima de tudo social, no qual a troca entre pessoas se realiza a todo tempo, que possui historicidade, ocasionando novos papéis sociais dos atores envolvidos.

PALAVRAS-CHAVE: Teoria do Turismo; Turismo Rural; Produção Associada ao Turismo; Impactos Sociais no Turismo.

\section{ABSTRACT}

We present the views carried out by different thoughts on the subject. Therefore, we will contribute by are interpretation of the schools of thought and interpretative frameworks, ways of systematization and mains tream tourism studies conducted by MCESCH (2004). Applying this thought to the explanation of the concept that guides the production associated with the use of rural space in tourism in units of production of family farming, in this context includes the study of the impacts on gender relations in the development of related activities. We use a documental analysis of an exploratory nature, with approach to tourism. We conclude that it is necessary to understand tourism as a social phenomenon, more than anything, in which the exchange takes place all the time between people, which has historicity resulting new social roles of the involved actors.

KEY-WORDS: Theory of Tourism; Rural Tourism; Production Linked to Tourism; Social Tourism Impacts 


\section{Introdução}

O presente artigo tem como eixo analítico os impactos socioculturais do turismo no espaço rural ocasionados pelo projeto de "produção associada ao turismo no uso do espaço rural em unidades de produção da agricultura familiar", do MTUR, compondo parte da pesquisa em andamento para a elaboração da dissertação de mestrado da autora.

Para o MTUR hoje os turistas buscam mais que belas paisagens e relaxamento, procuram experiências únicas, por meio do contato com os saberes e os afazeres típicos dos destinos escolhidos (MINISTÉRIO DO TURISMO - MTUR, 2011, p.3-4). Tais motivações encontram amparo na realidade brasileira, na medida em que, além da abundância dos atrativos naturais, o país também oferece o diferencial de sua gastronomia, de sua diversidade na produção cultural e a relevância de sua história. Apresentar a produção associada ao turismo no uso do espaço rural em unidades de produção da agricultura familiar, entendida como: "Qualquer produção artesanal, industrial ou agropecuária que detenha atributos naturais e/ou culturais de uma determinada localidade ou região, capazes de agregar valor ao produto turístico." (MINISTÉRIO DO TURISMO, 2011, p.18). E uma vantagem para atrair turistas e uma possibilidade de ampliar os canais de comercialização dos produtos de artistas, agricultores e artesãos residentes no espaço rural.

O MTUR (2011) pelo projeto produção associada ao turismo no uso do espaço rural em unidades de produção da agricultura familiar pretende diversificar a oferta turística ao projetar o país no cenário mundial visando o fluxo gerado pelos próximos eventos como a da Copa do Mundo de 2014 e as Olimpíadas de 2016, por meio de suas atividades diretamente ligadas ao setor, prioritariamente realizadas por micro e pequenas empresas, e de se beneficiar com ocasião tão favorável.

Apesar das oportunidades geradas mediante a produção associada ao turismo serem apresentadas como diferencial competitivo, outros fatores também são relevantes para observação, especialmente na produção desenvolvida no espaço rural pelo turismo. É importante lembrar que a realidade rural brasileira passou, e passa, por transformações significativas, como a pluriatividade. Neste novo arranjo, parte significativa dos trabalhadores rurais não permanece mais ocupada exclusivamente na agricultura, e o turismo aparece como atividade complementar.

Nesse sentido, procura-se entender o espaço rural e suas transformações a partir da modernização da agricultura; do advento da pluriatividade e sua produção associada. Além disso, busca-se compreender os papéis das mulheres campesinas enquanto sujieot da ação.

No contexto apresentado, a temática central deste artigo será uma reflexão acerca dos conceitos comumente aceitos para o turismo, suas especificidades e diversidades ao utilizar o território rural e as unidades de produção de agricultura familiar. Na tentativa de mover do enfoque da pesquisa em turismo a visão meramente economicista e trazer à tona o fenômeno social com implicações na vida cotidiana das famílias rurais, a pesquisa qualitativa é a possibilidade de aproximação pelo enfoque sociocultural, no qual estão inseridas também as relações de gênero que a partir das teorias de Scott (1989) é uma categoria socialmente construída, dentro de uma perspectiva histórica. Assim sendo, não se caracteriza por diferenciações biológicas, mas pelo aspecto social..

A temática justifica-se pela relevância dos impactos sociais e culturais do turismo, 
especialmente em pequenas comunidades rurais, e pelos escassos trabalhos com este foco. Nas últimas décadas, especialmente no Brasil, os territórios rurais são cada vez mais multifuncionais e pluriativos. Desta forma, o turismo surge como uma alternativa complementar do ponto de vista econômico, segundo visão do MTur, mas esta mesma política não só impacta sob esta faceta, como diretamente na organização familiar, portanto gerando impacto socioculturais, os quais pouco são levados em conta.

O objeto de análise tem por foco os impactos socioculturais do turismo em propriedades rurais caracterizada pela agricultura familiar. Conforme revelam dados do Censo Agropecuário do Instituto Brasileiro de Geografia e Estatísticas (IBGE) de 2006. Estes dados atestam que no território brasileiro há 4,3 milhões de estabelecimentos familiares, representando $84 \%$ das propriedades rurais do Brasil, os quais ocupam $74,4 \%$ da mão de obra do campo e de iniciativas públicas por meio dos programas desenvolvidos por MTUR e Ministério do Desenvolvimento Agrário (MDA), especificamente o Projeto Talentos do Brasil Rural: Turismo e Agricultura Familiar a Caminho dos Mesmos Destinos.

O projeto é resultado do Acordo de Cooperação Técnica assinado entre MTUR e MDA em outubro de 2009, durante a Feira Nacional da Agricultura Familiar, no Rio de Janeiro, cujo objetivo é implementar ações conjuntas que visem identificar, ordenar, promover e fortalecer a relação entre a agricultura familiar e a atividade turística.

Além desses ministérios, responsáveis pela concepção do projeto e pelo aporte financeiro (MDA) são parceiros: Ministério do Meio Ambiente (MMA), Serviço Brasileiro de Apoio às Micros e Pequenas Empresas (Sebrae/Nacional) e Agência de Cooperação Alemã (GIZ). No âmbito da execução do projeto se encontra o Sebrae-RS, mediante convênio com o MDA.

A estrutura do projeto possui dois eixos principais: produtos e serviços. Para o primeiro eixo, por meio de chamada pública, foram selecionados empreendimentos da agricultura familiar (associações e/ou cooperativas) com, no mínimo, 70\% de agricultura familiar. Igualmente, para o segundo eixo foram selecionadas instituições e entidades representativas de roteiros turísticos comercializados (grifo nosso), compostos por, no mínimo, $10 \%$ de empreendimentos da agricultura familiar.

O objetivo geral do Projeto Talentos do Brasil Rural é inserir produtos e serviços da agricultura familiar no mercado turístico, agregando valor à oferta turística brasileira. No tocante aos produtos da agricultura familiar - amenities (cosméticos), decorativos e utilitários (artesanato) e alimentos e bebidas -, almeja-se que estes sejam inseridos em meios de hospedagem, restaurantes, bares, lojas de artesanato e suvenires. No que diz respeito aos serviços, o intuito é preparar a propriedade familiar para receber turistas, dotando-a das condições necessárias para o desenvolvimento da atividade turística.

Essa investigação inicia-se com uma análise teórica conceitual de turismo, das políticas de turismo no espaço rural, observando as questões de pluriatividade e de especificidade da agricultura familiar, de suma relevância no contexto brasileiro, além da produção associada produzida no meio rural. Abordam-se também os principais conceitos e implicações do turismo no uso do espaço rural.

Por fim, apresenta-se a preocupação em formular uma proposta epistemológica, a qual rompa com os teóricos da visão empirista e pré-paradigmática, propondo-se o enfoque da prática social, além de presumir o diálogo interdisciplinar do turismo, ao reconhe- 
cer a diversidade de conhecimentos no interior de cada ciência. Além disso, procura-se ressaltar a relação entre a concepção de turismo do projeto de produção associada ao turismo no meio rural e seus impactos sociais na estrutura familiar.

\section{Turismo como fenômeno humano}

Para compreender o turismo enquanto fenômeno social faz-se necessário revisitar suas conceitualizações e implicações no território rural. Steinberger (2009) argumenta que o turismo é apenas mais um uso dentre os vários do território, ou seja, coexistem diferentes usos em um mesmo território; logo, o pensamento acerca do turismo deve considerar estes diferentes interesses.

Sendo a temática central da dissertação, em andamento o desvelamento das alterações dos papéis das mulheres campesinas em unidades de produção de agricultura familiar ao interagir com a inclusão da produção associada ao turismo, torna-se necessário contextualizar de qual turismo está-se tratando, haja vista a diversidade de compreensões, por vezes também conflituosas, acerca de sua conceitualização. Esta contextualização visa afastar do enfoque da pesquisa em turismo a visão meramente economicista e trazer à tona o fenômeno social, com implicações na vida cotidiana das famílias rurais.

Diante dos distintos posicionamentos teóricos acerca de turismo, serão tecidas algumas considerações a respeito das abordagens utilizadas para sua compreensão. Iniciando-se pelas análises empíricas em turismo, sistematizadas mediante estudos estatísticos especialmente voltados para oferta e demanda, em um determinado período, as quais reforçam a relevância econômica do turismo por meio de dados estatísticos e conceitos, cuja base são as primeiras definições de turista, sugeridas em 1937 pela Sociedade das Nações: "Pessoa que viaja por 24 horas ou mais por qualquer país distinto da sua residência habitual' (FUSTER apud MCESCH, 2004, p. 5), conceito reproduzido ao longo dos anos pela Organização Mundial de Turismo (OMT), restringindo a experiência turística para os sujeitos que necessariamente permaneciam mais de 24 horas fora de seu local de moradia.

O mesmo ocorre com os conceitos apresentados por Mclntosh (2002 apud MCESCH, 2004), em que turismo também pode ser definido como pessoa fazendo viagens, abrangendo transportes, hospedagem, serviços de alimentação e outras atividades relacionadas ao viajante e àqueles que estejam lhe prestando serviços.

Posteriormente, novos conceitos foram apresentados tanto para turista quanto para turismo. O conceito de turismo elaborado pela OMT, em 1998, o reduz à atividade econômica e comercial e não permite desvelar a essência do fenômeno, além de abster-se de qualquer preocupação com as implicações sociais.

El Turismo compreende las actividades que realizan las personas durante sus viajes y estâncias en lugares distintos a su entorno habitual, por un período de tiempo consecutivo inferior a un año, con fines de ócio, por negócios y otros (SANCHO, 1998, p.44).

O turismo, desde os primeiros estudos, não é compreendido como ciência. Estes estudos basearam-se em diferentes ciências para investigar sua relevância, especialmen- 
te as voltadas para a área econômica, contudo, as metodologias econométricas foram insuficientes para explicá-lo como um fenômeno social. Dentro deste contexto de apreensão do turismo, a OMT e autores como Fuster e Mclntosh, tendo em vista seus respectivos momentos históricos, não se preocuparam em conhecer o objeto de estudo além de sua aparência, restringindo suas análises à utilidade do turismo para o desenvolvimento econômico, a partir da relação produção-acúmulo-consumo. São poucas, ou quase nulas, as contribuições de estudos na questão social, da qual é parte inseparável, até os anos 1960 (MCESCH, 2004).

Ao entender o turismo como um fenômeno social sua epistemologia recai sobre a compreensão das ciências sociais, o que reporta sua análise sob uma concepção teórica interdisciplinar e de cunho social. Para tecer a compreensão científica do turismo precisamos colocá-lo como fenômeno no campo da ciência em sua concepção não mais cartesiana e sim na ótica da complexidade.

Para Morin (2000), a ciência é complexa, pois é inseparável seu contexto histórico e social. Na ciência moderna, uniu-se a efervescência cultural da Renascença à efervescência econômica, política e social do Ocidente europeu dos séculos XVI e XVII. Assim sendo, de forma progressiva, a ciência se alia à técnica permeando diferentes esferas, como universidades, empresas e sociedades.

A nova perspectiva de pensamento é de uma ciência como conhecimento vivo, segundo Morin (op. cit.). Sua complexidade não permite aceitar que a ciência produz apenas benefícios, será necessário rever as verdades absolutas, nas quais inclui-se também a temática deste artigo. É necessário entender a complexidade da realidade e fundamental refletir acerca de qual conceito de ciência se está partindo. Além disso, o autor propõe o desenvolvimento da ciência a partir da comunicação entre as diferentes ciências, a transdisciplinaridade, uma vez que não se deve separar aquilo que por essência está unido.

A preocupação em definir turismo não é exclusiva de pesquisadores da área acadêmica. Por se tratar de prática social com potencial econômico, o mercado necessita formalizar sua importância na perspectiva econômica. Diante de tal constatação, em diferentes países surgem conceitos com a intenção de explicar este fenômeno complexo, embora simples à primeira vista.

Para normatizar suas práticas é criada a OMT, entretanto seus estudos permanecem, quase que essencialmente, voltados às estatísticas de demanda e oferta turísticas, ou seja, os indicadores numéricos ainda são a principal fonte de evidências para justificar sua importância. Desta forma, no cenário mundial, o turismo desponta, já nas últimas décadas do século $\mathrm{XX}$, como relevante especialmente para a balança comercial, e são estes os indicadores usualmente utilizados para compreensão do fenômeno.

As limitações para entender o fenômeno de forma complexa perpassam as políticas de turismo no espaço rural, recentes no cenário brasileiro. No Brasil, a criação do MTUR, em 2003, e a publicação de seu primeiro Plano Nacional de Turismo: Diretrizes, Metas e Programas, em abril do mesmo ano, revelam uma concepção de turismo como elemento propulsor do desenvolvimento sócio-econômico do país (MTUR, 2003). 
Apesar das mudanças de governantes no âmbito nacional, os documentos balizadores das políticas públicas ainda permanecem pautados na visão economicista do fenômeno turístico, conforme destacamos a seguir "Esta é uma atividade econômica que envolve relações entre pessoas, oportuniza a criação de pequenas e médias empresas" (MTUR, Sebrae, Associação de Culturas Gerais, 2011, p.16, grifo nosso).

O fenômeno obteve tratamento reducionista, objetividade absoluta para definições, precisão de números, como se houvesse um mundo ideal; até mesmo o saber turístico tornou-se mercantilizado e facetado, ou seja, a análise deteve-se nas partes, havendo separação do todo, e não observou sua complexidade, permanecendo na superfície da investigação de sua episteme, restringindo a uma concepção funcionalista apresentada a seguir.

Os estudos de Fuster (1974 apud MCESCH, 2004) são pautados na relevância de descrever um fato turístico, no entanto, não há preocupação em apreender acerca de seu surgimento, como são seus processos nem suas consequências. Ele compreende turismo como parte do sistema capitalista, o qual necessitaria do ócio e do lazer para manter a saúde do indivíduo. Em outras palavras, o sujeito é uma máquina e o descanso, a compensação pelo trabalho executado. Portanto, uma vez parte integrante do sistema, é primordial para garantir sua manutenção e seu funcionamento.

De forma geral, a análise funcionalista expressa por Fuster revela-se conservadora, ao conceber o turismo de maneira facetada e não considerar a historicidade do fenômeno social, fortalecendo a concepção de normas, desempenho de papéis, ou seja, as funções que o turismo deve exercer.

Relativamente à concepção de pré-paradigmáticos, Mœsch (2004) aponta autores como Sessa (1984), Molina (2000), Lainé (1985) e Beni (1998), os quais se utilizam de teorias sistêmicas na tentativa de compreender o objeto turístico. O termo "préparadigmático" é uma maneira adotada pela autora para classificar os teóricos do turismo, a qual ressalta que os objetos de estudo resultam de um dado momento, e por isso possuem historicidade.

Segundo Sessa (op. cit.) apud Mœsch (op. cit.), turismo é um fenômeno complexo e inerente à sociedade industrial, e justamente por sua concepção econômica impossibilitou sua compreensão. A própria insuficiência da abordagem econômica para a compreensão do turismo como um todo permitiu o surgimento da abordagem sistêmica como alternativa de compreendê-lo.

A interpretação do autor, a partir da concepção de Van Doorn (1982), é a de que os estudos em turismo estão pautados em elementos tais como: turista; indústria turística (grifo nosso) e serviços intermediários utilizados pelos turistas; oferta de recursos turísticos; e cenário social do turismo. Ou seja, estes estudos estão pautados em alterações sociais, culturais, tecnológicas e políticas que interagem com os fluxos turísticos das regiões, no intuito de diminuição das diferenças regionais, mas dando continuidade a uma concepção de turismo reduzida ao processo da oferta e demanda.

Sua metodologia sistêmica apreende o objeto como produto, não como processo sequencial vivo, e está ligada à noção de modelo, pois concebe turismo meramente como atividade de serviços, sem maior compreensão sociocultural. 
Para Sessa (op. cit.), o turismo faz-se necessário à construção de planos e programas de desenvolvimento pautados na racionalidade, rompendo com o empirismo vigente à época, em virtude dos impactos causados por esta atividade. O autor, contudo, não deixa sua visão positivista, influenciada pelo próprio capitalismo e impregnada na concepção do fenômeno turístico. Além disso, aproveita a denominação de polos industriais, transpondo-na como modelo aos polos turísticos, reforçando ainda mais a visão do turismo como indústria em que este possibilitaria transferências de riqueza das regiões mais ricas para as mais pobres, na relação oferta-demanda, o que leva a comparar a semelhança com o projeto ora estudado.

Quanto ao turista, o autor o destaca também como agente que busca reequilíbrio biológico, físico, espiritual nas regiões turísticas, além de, em contrapartida, estabelecer com as regiões por ele visitadas fluxos monetários. Este intercâmbio contribui para que os fluxos de saída se transformem em renda, consumo, poupança e investimento. Para o autor é preciso compreender as regiões turísticas como polos turísticos de trocas econômicas, informacionais e culturais. Tal visão vem a ser sua grande contribuição metodológica, pois ao utilizar a escala região para análise sistêmica do turismo contribui para o estabelecimento do modelo de polos turísticos, bastante utilizado a partir da década de 1970 no planejamento nacional. Este modelo de compreensão, contudo, não avançou para uma análise social.

Dentro da análise teórica referente ao turismo, têm-se os pré-paradigmáticos como Molina (2000), que se utiliza do quadro interpretativo fenomenológico. Em sua interpretação, atribui-Ihe um sentido humano. Para a fenomenologia, a experiência possui dois polos: 0 ato de perceber e o objeto de sua percepção. A consciência permitirá atribuir significação, ou sentido, a cada objeto. Neste momento a totalidade é enfatizada, pois se deseja buscar a essência dos objetos e de suas manifestações, a partir da experiência humana, do vivido.

A realidade não é tida como algo objetivo, é entendida como emergente da intencionalidade da consciência voltada para o fenômeno. O modelo fenomenológico para o turismo, na perspectiva de Molina (2000), encontra seu ponto de partida no ócio. Entretanto, é imprescindível que exista um autêntico tempo livre, de outra maneira não haverá ócio turístico.

O modelo fenomenológico, suas metodologias e tecnologias devem reconhecer uma concepção geral do homem, de alcance universal, mas deve situar-se no presente histórico que caracteriza as sociedades, reconhecendo sua estrutura social e os fatores políticos, econômicos e culturais que as influenciam.

Para compreender o turismo como totalidade, o autor apresenta a análise geral de sistemas, sendo este orgânico, um todo, seja ele corpo social ou organização. Na compreensão de Molina (op. cit.), no sistema as relações não são causais (causa e efeito) e sim circulares (complexas), compreendendo a parte do todo e as inter-relações das partes, não sendo possível conhecê-las de forma isolada. Compreende, além disso, que este processo é relevante para o conhecimento turístico, pois enfatiza um modo de pensamento holístico.

A interpretação do autor foi válida, no entanto, reiterando Mœsch (2004), ele não consegue superar o próprio determinismo econômico, mesmo com a utilização da análise de sistemas, pois nesta o turismo nutre uma preocupação exaustiva com a lógica da prova, como manifestação econômica, em uma tentativa de manter posição na comunidade científica. A economia não deixa, portanto, de ser o foco de sua análise e ocupa também o espaço cultural. Desta forma, não é possível dissociar sua concepção de ciência ideal da de um modelo de mundo real, a partir das evidências empíricas dos fenômenos. 
Como fator relevante deste artigo, as mulheres campesinas interagem com novos atores, ou seja, com os turistas, por meio do território rural, utilizado para o turismo. Estas interações, por conseguinte, sofrem interferências nas mais variadas áreas sociais, indo desde as comportamentais até mesmo as de cunho familiar, não sendo possível estudar tal fenômeno somente por uma ótica, a do emissor ou a do receptor, e muito menos restringir o estudo a seu aspecto econômico, pois ele é, acima de tudo, marcado pelas relações sociais. No caso estudado, estas relações ocorrem no espaço rural, que possui suas próprias especificidades nas relações de gênero.

No cenário brasileiro, Beni (1998 apud MCESCH, 2004) foi quem, até o momento, deixou a maior contribuição conceitual de análise estrutural do turismo. Para ele, o sistema turístico é um conjunto de partes que interagem, e o seu modelo de construção para compreensão do objeto parte da realidade de observações e/ou medições. Desta forma, na tentativa de aproximação com a ciência, busca exatidão. A proposta do autor é que o turismo seja entendido como um sistema composto de três conjuntos: relações ambientais (com os subsistemas ecológico, social, econômico e cultural); organização estrutural (com os subsistemas superestrutura e infraestrutura); e ações operacionais (com os subsistemas mercado, oferta, demanda, produção, distribuição e consumo).

Para Beni (op. cit.) é fundamental ampliar a discussão por meio de bases sólidas para interpretação crítica do turismo. Suas proposições não constituem uma cientifização do turismo, e sim um instrumento para que pesquisadores do tema continuem tentando aproximação com este fenômeno social complexo e especialmente interdisciplinar.

Mœsch (2004) contribuiu para essa mudança de perspectiva ao romper com a episteme apresentada pelos autores anteriormente descritos. Tanto o primeiro momento, dos estudos da pré-ciência, no contexto dos empiristas positivistas, quanto o segundo momento, dos pré-paradigmáticos, expõem uma proposta de epistemologia social do turismo. Tal proposição se pauta no entendimento do turismo como um campo de práticas históricas e sociais.

A proposta da autora é efetivar a discussão em abordagem interdisciplinar, que requer uma metodologia capaz de compreender que não só a parte está no todo, senão que, também, o todo está na parte, que permanece singular.

A origem da proposta está na realidade prática da história e da sociedade pósmoderna, na qual o econômico e o tecnológico são o resultado das necessidades subjetivas do imaginário, da diversão, da comunicação e da ideologia, da criação dos sujeitos, e por eles são consumidos, no intuito de religar o mundo objetivo e subjetivo.

A perspectiva é pensar o sujeito de forma complexa. Ele é produtor e consumidor, e desta forma se estabelece a lógica da atração social, ou seja, o estar junto. O desafio é resistir à realidade de atividade econômica e mercadológica imposta ao turismo, tida como evidente, romper com os autores que não possuiam qualquer preocupação epistemológica, como os empíricos positivistas, e superar a abordagem do paradigma sistêmico, para o qual o sistema econômico suplanta todos os demais sistemas, na perspectiva de caminhar para a compreensão do turismo como um fenômeno social que implica em processos de contradição na relação entre seus atores e o meio ambiente em que esta prática se efetiva. 
Para Certeau (1982) prática social não possui o mesmo sentido nos diferentes períodos históricos. A compreensão do turismo enquanto prática social, atendidas as especificidades deste artigo, coloca-o sob as relações de um sistema aberto. Daí seu conteúdo interdisciplinar. Teórica e empiricamente o conceito de sistema aberto abre a porta a uma teoria da evolução, que não pode derivar mais que de interações entre sistema e ecossistema e que, em seus laços mais notáveis, pode ser concebido como um transbordo do sistema em um metassistema.

O objetivo dessa abordagem é permitir uma reflexão teórica que possibilite compreender a intencionalidade de seus pensadores, bem como suas limitações e contribuições, além da transposição para o entendimento dos impactos provocados no espaço rural, ampliando, dessa forma, a visão dos efeitos econômicos e buscando novas percepções sobre as políticas públicas sob o chamado "turismo rural".

\section{Turismo como uso do espaço rural}

Além da definição de turismo propriamente dita, no decorrer de sua trajetória como prática social outras definições foram construídas nos últimos anos, como a de turismo rural e agricultura familiar, adotados pelo MTUR, órgão responsável pela política nacional de turismo, e pelo MDA, órgão responsável pela ampliação das políticas públicas para o fortalecimento da agricultura familiar.

O turismo na agricultura familiar é considerado uma atividade econômica complementar à renda dos agricultores, contribuindo para diversificar suas formas de trabalho, agregar valor à produção agrícola ou artesanal, ampliar a geração de trabalho e renda e contribuir para a preservação do meio ambiente, o resgate das tradições, técnicas e processos produtivos e a valorização da cultura local.

O MTUR adota a conceituação cujos fundamentos são construídos a partir de aspectos que se referem ao turismo, ao território, à base econômica, aos recursos naturais e culturais e à sociedade. Desta forma, define-se que:

Turismo Rural é o conjunto de atividades turísticas desenvolvidas no meio rural, comprometidas com a produção agropecuária, agregando valor a produtos e serviços, resgatando e promovendo o patrimônio cultural e natural da comunidade (MTUR, 2003, p. 11).

É importante ressaltar que outras terminologias são amplamente utilizadas no Brasil para designar atividades de turismo desenvolvidas no âmbito do espaço rural - agroturismo, agroecológico, campestre, por exemplo - no entanto, no contexto deste artigo, a designação adotada será a de turismo rural na agricultura familiar (TRAF), conforme segue:

É a atividade turística que ocorre no âmbito da unidade de produção dos agricultores familiares que mantêm as atividades econômicas típicas da agricultura familiar, dispostos a valorizar, respeitar e compartilhar seu modo de vida, o patrimônio cultural e natural ofertando produtos e serviços de qualidade e proporcionando bem estar aos envolvidos (GRAZIANO DA SILVA, 1998 apud MTUR, 2010, p. 21). 
Tal conceito é utilizado pelo MTUR, em parceria com MDA, com o intuito de apoiar a estruturação de roteiros turísticos que contemplem a agricultura familiar e a inserção de produtos produzidos no âmbito destas propriedades, entre os quais constam alimentos, bebidas, artesanato, para inserção no mercado turístico (MTUR, 2010). Embora ainda esteja em fase inicial do seu potencial de aproveitamento, observa-se que os fluxos turísticos para a periferia estão cada vez mais intensos, confirmando a tendências de crescimento desse segmento turístico. A tabela a seguir apresenta dados da pesquisa denominada "Hábitos de consumo do turismo brasileiro", aplicada pelo Vox Populi em 2009 para o MTUR, a pesquisa foi realizada por telefone, em 11 capitais do país: São Paulo (SP), Rio de Janeiro (RJ), Belo Horizonte (MG), Porto Alegre (RS), Curitiba (PR), Florianópolis (SC); Salvador (BA); Recife (PE); Fortaleza (CE); Brasília (DF) e Goiânia (GO), a qual enfatiza a importância do turismo rural. Entre as opções, "campo" é o destino preferido por $13,5 \%$ dos turistas abordados, perdendo apenas para "praias", com $64,9 \%$ da preferência.

Tabela 1: lugares preferidos dos turistas brasileiros atuais ${ }^{1}$

Table 1: favorite places for tourists current Brazilian.

\begin{tabular}{|l|l|l|}
\hline \multirow{2}{*}{ Praia } & \multicolumn{1}{|c|}{ Primeira citação } & Soma ponderada \\
\hline Campo & \multicolumn{1}{|c|}{$64.9 \%$} & $45.1 \%$ \\
\hline Cidades históricas & $13.5 \%$ & $19.2 \%$ \\
\hline Montanhas & $12.0 \%$ & $18.4 \%$ \\
\hline Outras respostas & $8.1 \%$ & $15.5 \%$ \\
\hline
\end{tabular}

Fonte: MTUR/Vox Populi (2009).

Source: MTUR/Vox Populi (2009).

Para fundamentar a construção e os instrumentos de políticas públicas voltadas para o meio rural, no âmbito do governo federal, algumas tentativas vêm sendo realizadas. Como exemplo, tem-se o MDA, que adota um conceito que pode referenciar as ações relacionadas ao turismo no espaço rural. Nesse sentido, os territórios rurais são compreendidos como:

[...] um espaço físico, geograficamente definido, não necessariamente contínuo, caracterizado por critérios multidimensionais, tais como o ambiente, a economia, a sociedade, a cultura, a política e as instituições, e uma população, com grupos sociais relativamente distintos, que se relacionam interna $\mathrm{e}$ externamente por meio de processos específicos, onde se pode distinguir um ou mais elementos que indicam identidade e coesão social, cultural e territorial. Predominância de elementos "rurais", sobretudo a paisagem e os elementos constitutivos da cultura, valores, história e economia (MDA, 2005).

A sociedade contemporânea concebe o meio rural com características gerais e predominantemente pela destinação da terra. Com base nesta referência, é válido ressaltar que os territórios rurais abrigam diferentes experiências e atividades conforme Grazia- 
no da Silva et al. (2000, p.19):

[...] a denominação "turismo em áreas rurais" para englobar não só aquelas atividades de serviços não-agrícolas, tradicionalmente denominados de "turismo rural ou agroturismo" (aqui usados como sinônimos), como também as de lazer realizadas no meio rural, denominadas de turismo ecológico ou "ecoturismo", turismo de negócios e turismo de saúde.

Muitas das práticas de lazer e outras atividades executadas nesse meio não são necessariamente turismo rural. Sendo assim, compreende-se o espaço rural como um recorte geográfico no qual o turismo rural ocorre (BRASIL, MINISTÉRIO DO TURISMO, 2010, p. 20)..

O Ministério do Turismo (BRASIL, 2010), na revisão das orientações básica para turismo rural, descreve as atividades de turismo rural constituídas da oferta de serviços, equipamentos e produtos turísticos, como: hospedagem; alimentação, entre outras.

Ainda nessa revisão, o ministério destaca que a concepção de meio rural que adota baseia-se na noção de território, com ênfase no critério da destinação da terra e na valorização da ruralidade, ou seja, no valor que a sociedade contemporânea atribui ao rural. Tal valor contempla as características mais gerais do meio rural: produção territorializada de qualidade, paisagem, biodiversidade, modo de vida, lógica familiar, cultura comunitária, identificação com os ciclos da natureza (BRASIL, MINISTÉRIO DO TURISMO, 2010, p. 20).

Assim sendo, apresenta ainda comprometimento com a produção agropecuária, revelando a existência da ruralidade, de um vínculo com as coisas da terra. Desta forma, mesmo que as práticas eminentemente agrícolas não estejam presentes em escala comercial, o comprometimento com a produção agropecuária pode ser representado por meio das práticas sociais e de trabalho, do ambiente, dos costumes e tradições, dos aspectos arquitetônicos, do artesanato, do modo de vida, considerados típicos de cada população rural.

Agregação de valor a produtos e serviços está relacionada à hospitalidade em ambiente rural, permitindo que as características rurais passem a ser entendidas sob outra perspectiva, que não apenas a da produção primária de alimentos.

Agregar valor também se faz presente pela possibilidade de verticalização da produção, ou seja, beneficiamento de produtos in natura (ovos, verduras, frutas), transformando-os para que possam ser oferecidos ao turista, sob a forma de conservas, embutidos, produtos lácteos, refeições e outros. Outra possibilidade é a transformação artesanal de resíduos e insumos do campo em utilitários e objetos decorativos carregados de história e tradições.

O turismo rural, além do comprometimento com as atividades agropecuárias, caracteriza-se pela valorização do patrimônio cultural e natural como elementos da oferta turística. Assim, os empreendedores, na definição de seus produtos de turismo rural, devem contemplar com a maior autenticidade possível os fatores culturais, por meio do resgate das manifestações e práticas regionais (como o folclore, os trabalhos manuais, os 
costumes, os ofícios, as festas, os "causos", a culinária) e primar pela conservação do ambiente natural, da paisagem e cultura (o artesanato, a música, a arquitetura).

De acordo com o MTUR (2010), as definições apresentadas acima explicitam que a expressão "turismo no espaço rural" se refere a todos os movimentos turísticos ocorridos no espaço rural, ao passo que o termo turismo rural se restringe às características próprias do meio rural, à paisagem, ao estilo de vida e à cultura rural, excluindo-se formas não ligadas à prática e ao conteúdo rurais.

Independentemente desses conceitos e critérios, é fato que a atual conjuntura tem gerado mudanças comportamentais no modo de vida das pessoas, não importa se rurais ou urbanas. Isso tudo vem influenciando, também, as necessidades de turismo ora demandadas. Assim, quando se pensa em opções de turismo, o retorno à tranquilidade da vida no campo como uma forma de aliviar as tensões provocadas pelo cotidiano dos grandes centros urbanos está em ascensão.

Cavaco (apud GRAZIANO DA SILVA et al., 2000, p.26-30) relata ensinamentos a partir das experiências europeias de desenvolvimento local, descritas abaixo:

\begin{abstract}
Em síntese, para lá do crescimento econômico (...) importa o desenvolvimento, que é simultaneamente econômico e social, e também territorial, e envolve processos de mudança estrutural, produção social significativa, redistribuição mais equilibrada da riqueza, melhoria dos rendimentos, das condições de vida e das expectativas, sobretudo dos grupos sociais menos favorecidos.
\end{abstract}

A autora utiliza, com base no conceito de regeneração do rural utilizado por Leal (1995), um novo papel para o meio rural, após resolvida a questão do abastecimento alimentar, que para o mundo ocidental é função primária dos espaços rurais. Desta forma, a autora propõe novas funções não agrícolas do meio rural, entre as quais estão inclusos equilíbrio do uso do território, de forma a compensar os efeitos do despovoamento, como seu uso para atividades de lazer, entre outras. O meio ambiente, seja natural ou construído, é ferramenta de trabalho para o turismo, e sua conservação se vincula com a garantia da atividade a longo prazo.

Entende-se que o espaço rural é a retomada do futuro mais harmônico entre o natural e construído para os cidadãos de áreas urbanas. Vivenciar estas áreas mais isoladas, que possuem valores humanos imensuráveis, a custos não necessariamente dispendiosos, como cita a autora.

Segundo Campanhola (1999) e Graziano (1999), a agricultura não poderá ser a única base econômica para o desenvolvimento do meio rural em longo prazo, e estratégias econômicas alternativas já são evidenciadas em muitos países para manter o homem no campo. O turismo como uso do meio rural poderá ser um dos vetores do desenvolvimento local, respeitando que as decisões sejam tomadas pela comunidade, que o controle sobre os processos de desenvolvimento seja desempenhado por atores sociais e que as comunidades locais se apropriem dos benefícios gerados.

Conforme já se apresentou anteriormente e assinala o MTUR, é preciso compreender as heterogeneidades regionais e as diferenças no estágio de desenvolvimento das diversas iniciativas de turismo empreendidas nos territórios rurais brasileiros. Em decor- 
rência deste entendimento, sem o intuito de minimizar tais questões, o Ministério constrói estratégias de consolidação do turismo rural, agrupando sob o mesmo conceito as definições de agroturismo e turismo na agricultura familiar.

É possível concluir que o recente interesse pelo segmento por parte do governo e do próprio setor privado se deve ao fato de esta atividade ser uma alternativa para manter os trabalhadores rurais no campo, juntamente com o significativo aumento do interesse de moradores de regiões urbanas em conhecer a ruralidade. Os contrastes entre as regiões a cada dia diminuem, contudo, é evidente que o contato com a terra e com a natureza sempre será um atrativo diferenciador.

Ao complementar a renda da agricultura familiar, o turismo rural pode garantir a sustentabilidade econômica, social e cultural, agregando valor ao seu patrimônio cultural, ao conservar a culinária local, as tradições de músicas, danças, costumes, entre outros, assevera o MTUR. Para a sustentabilidade social é importante ressaltar a nova dinâmica dos estabelecimentos rurais que exercem atividades turísticas, com a inserção das muIheres rurais neste contexto sob a condição de ser social. Nesta pesquisa, em andamento, há a intenção de verificar quais as alterações dos papéis das mulheres campesinas diante do advento do uso do turismo no espaço rural e de sua produção associada.

\section{Evidências preliminares}

As impressões apresentadas a seguir refletem percepções inconclusas, uma vez que este artigo é parte de uma dissertação de mestrado em andamento e a pesquisa se encontra em fase de análise.

Ao longo deste artigo evidenciou-se que o mercado aqui compreendido como capital, por muito tempo ditou, e ainda hoje dita, o que se deve pensar como teoria do turismo, não sendo o único. As organizações e representações internacionais e nacionais do turismo também estão impregnadas e alienadas pelo processo econômico e mercadológico. Desta maneira, infere-se que compreender os autores que em algum momento tentaram superar o que estava posto é primordial e riquíssimo para este trabalho, sendo fonte de inspiração para todos os estudiosos do fenômeno turismo.

Destaca-se, ainda, que as discussões e reflexões em torno de uma epistemologia social do turismo são fundamentais para construir um arcabouço teórico conceitual sólido, de modo a permitir a compreensão da complexidade e interdisciplinaridade do turismo em sua essência humana e o entendimento de suas implicações e práticas como fenômeno social.

Dessa forma, para conhecer a realidade que se apresenta em constante modificação é necessária uma ciência aberta ao novo, que possibilite ferramentas de aproximação com o fenômeno que é essencialmente humano.

A partir da pesquisa exploratória da dissertação em andamento realizada junto aos roteiros "Caminhos da Roça - Socorro/SP" e "Trekking Travessia Leste - Alto Paraíso/GO" do projeto do MTUR, evidenciou-se preliminarmente que a inserção da mão de obra feminina no turismo rural colabora para a ampliação de sua renda e para a sua importância econômica no meio familiar. Essa nova configuração é facilitada 
pelo fato de as práticas da atividade turística, considerando o uso do território rural, assemelharem-se ou coincidirem com as tarefas domésticas - outrora apontadas como inferiores, ou seja, desvalorizadas em relação a outras atividades exercidas predominantemente por homens. Dessa forma, assiste-se a uma valorização da participação da mulher na atividade turística no campo.

O contato com turistas também é fator decisivo para estas mudanças, pois a trabalhadora rural tanto pode incorporar hábitos e costumes de outras populações como se desfazer de alguns de seus costumes e tradições.

Dessa forma questiona-se o papel do turismo rural no aumento do empoderamento feminino, proporcionado pela renda e pelas novas perspectivas de consumo, alterando, por conseguinte, a hierarquia econômica familiar.

Ao analisar a questão da história e da memória no contexto da mulher campesina como sujeito da ação, conclui-se que é relevante pensar na incoerência de se justificar o presente por meio do passado e que a memória se faz necessária para que não sejam apagadas atrocidades, violações, ou mesmo as tradições. Percebeu-se que, mesmo com o advento da atividade turística ao espaço rural, as famílias rurais possuem uma história anterior com a terra, os animais, os afazeres e as tradições que não poderá ser esquecida, contudo estão sendo constantemente recriadas.

As leituras mostraram que para resistir às modificações no espaço rural não é preciso fechar as portas e esquecer o que se passa no mundo. É possível resistir sem abrir mão da valorização de sua poesia, sua música e sua cultura, ou seja, sem renunciar sua identidade rural. Sob esta nova perspectiva, a orientação é estudar também a coragem, a esperança e por vezes a felicidade de determinados grupos, especialmente das campesinas, as quais podem ter novos papéis sociais, em virtude da atividade turística e da produção associada no território rural.

Destarte, compreender sua nuances e tentar desvelar que tipo de papéis foram reconstruídos é o desafio que instiga a pesquisa em andamento, sendo o recorte deste artigo apenas um dos enfoques possíveis para a problemática em questão.

Por fim, se estivéssemos arraigados à concepção economicista e mercadológica do turismo, o desenvolvimento deste projeto não seria possível. A concepção aqui adotada é, doravante, a de turismo como fenômeno acima de tudo social, em que a troca entre pessoas se realiza a todo tempo e o qual possui historicidade, deixando sempre um legado aos envolvidos.

\section{Referências bibliográficas}

BRASIL. Relatório da pesquisa de hábitos de consumo do turismo brasileiro. Vox Populi, MTUR, 2009.

BRASIL. Censo Agropecuário - agricultura familiar 2006. Instituto Brasileiro de Geografia e Estatística Disponível em: <http://www.ibge.gov.br/home/presidencia/noticias/ noticia impressao.php?id noticia=1466>.Acesso em: 16/6/2011. 
BRASIL. Diretrizes para o desenvolvimento do turismo rural. Brasília: Ministério do Turismo, 2003.

BRASIL. Manual para o desenvolvimento e a integração de atividades turísticas com foco na produção associada. Brasília: Ministério do Turismo, Serviço de Apoio às Micro e Pequenas Empresas, Associação de Cultura Gerais, 2011.

BRASIL. Ministério do Turismo - Missão. Brasília: Ministério do Turismo, 2012. Disponível em: <http://www.turismo.gov.br/turismo/o_ministerio/missao/>. Acesso em: 15/04/2012.

BRASIL. Plano Nacional de Turismo: diretrizes e metas e programas 2003-2007. Brasília: Ministério do Turismo, 2003.

BRASIL. Plano Nacional de Turismo: uma viagem de inclusão 2007-2010. Brasília: Ministério do Turismo 2007.

BRASIL. Referências para uma estratégia de desenvolvimento rural no Brasil. In: Série Documentos Institucionais n.ำ 1 - SDT. Brasília: Ministério do Desenvolvimento Agrário, 2005.

BRASIL. Secretaria de Agricultura Familiar - missão. Brasília: Ministério do Desenvolvimento Agrário, 2012. Disponível em: <http://portal.mda.gov.br/portal/saf/institucional/ institucional>. Acesso em: 15/04/2012.

BRASIL. Turismo rural: orientações básicas. Brasília: Ministério do Turismo, Secretaria Nacional de Políticas de Turismo, Departamento de Estruturação, Articulação e Ordenamento Turístico, Coordenação Geral de Segmentação. 2ed. Brasília: Ministério do Turismo, 2010.

CAMPANHOLA, C.; SILVA, J.G. Panorama do turismo no espaço brasileiro: nova oportunidade para o pequeno agricultor. In: CONGRESSO BRASILEIRO DE TURISMO RURAL: Turismo no espaço rural brasileiro, 1999, Piracicaba. Anais... Piracicaba: FEALQ, 1999, 239p.

CAVACO, C. Turismo rural e desenvolvimento local. In: RODRIGUES, A. (Org.). Turismo e Geografia: reflexões teóricas e enfoques regionais. São Paulo: Huitec, 1996.

DE CERTEAU, M. Práticas históricas e práxis social. In. A escrita da história. Rio de Janeiro: Forense Universitária, 1982.

GRAZIANO DA SILVA, J. et al. Turismo em áreas rurais: suas possibilidades e limitações no Brasil. In: ALMEIDA, J.A. et al. (Org.). Turismo rural e desenvolvimento sustentável. $2^{\underline{a}}$ ed., Campinas: Papirus, 2000.

MCESCH, M.M. Epistemologia social do turismo. Tese (doutorado). Escola de Comunicação e Artes/Universidade de São Paulo, São Paulo, 2004.

MOLINA, S. Conceptualización del Turismo. Limusa, México: 2000.

MORIN, E. Ciência com consciência. Tradução de Maria de Alexandre e Maria Alice Sampaio Dória - Ed. Revista e modificada pelo autor 4ํㅡㄹ ed. - Rio de Janeiro: Bertrand Brasil, 2000. 
SANCHO, A. (Dir). Introducción al turismo. 1ํㅡㄹ ed. Madrid: Organización Mundial del Turismo, 1998.

SCOTT, J.W. Gênero: uma categoria útil de análise histórica. Recife: SOS Corpo. 1989

STEINBERGER, M. (Org.). Territórios Turísticos no Brasil Central. Brasília: LGE Editora, 2009.

\section{Nota:}

${ }^{1}$ Consumidores que compraram serviços de turismo em pacotes ou em partes nos dois nos dois anos anteriores à realização da pesquisa.

Maysa Sena de Carvalho: Universidade de Brasília, Brasília, DF, Brasil.

Email: maysacarvalho2011@gmail.com

Link para o currículo Lattes: http://lattes.cnpq.br/5479678217085847

Marutschka Martini Mœsch: Universidade de Brasília, Brasília, DF, Brasil.

Email: marumoesch@hotmail.com

Link para o currículo Lattes: http://lattes.cnpq.br/4591055346328481

Data de submissão: 31 de maio de 2012

Data de recebimento de correções: 11 de dezembro de 2012

Data do aceite: 08 de abril de 2013

Avaliado anonimamente 